\title{
The Impact of Cross-Disciplinary Culture on Student-Supervisor Perceptions
}

\author{
Gina Wisker \\ University of Brighton, \\ Brighton, UK
}

g.wisker@brighton.ac.uk

\author{
Silwa Claesson \\ University of Gothenberg, \\ Gothenberg, Sweden
}

silwa.claesson@.ped.gu.se

\begin{abstract}
Global increases in the numbers of postgraduate students, their growing cultural diversity, and an emphasis on skill development and time to completion are accompanied by an increase in the numbers of supervisors and a professionalization of the training and development processes for both postgraduates and supervisors. Much research on supervision considers variations in practice from the perspective of the traditional functional, dyadic relationship. Other work considers power relations, research communities, and cultural diversity. This research focuses on 'fields of tensions' in discipline culture, identified by supervisors and facilitators on a supervisor development program on which both authors have taught. The research makes use of data from participant assessment responses, or course papers, and focused interviews with participants. 'Fields of tension' emerge in the design, actioning, and completion of the research project and in the shape and expression of the thesis, which we argue are inflected by the different disciplinary cultures in which supervisors and students locate research. Disciplinary differences and 'fields of tension' also emerge in the perceptions of differences in supervision, expectations of roles, relationships, and balances of power in the supervisor-student relationship. This paper examines the cultural differences in academic disciplines and how this is reflected in the supervisory process. We suggest that open sharing and discussion of such disciplinary differences and 'fields of tension' in supervisor development programs can enable vital, valuable, metacognitive awareness of supervision and research practices for supervisors and their students.
\end{abstract}

Keywords: supervision, doctoral, discipline, diversity, professional practice

\section{Introduction}

In the context of increasing postgraduate numbers and supervisor numbers, universities worldwide are focusing on development programs for postgraduates and professionalization of the supervisory role. Research and publications on the supervision process are also increasing in number, and the content diversifying as new issues emerge, such as cultural diversity, the range of

Material published as part of this publication, either on-line or in print, is copyrighted by the Informing Science Institute. Permission to make digital or paper copy of part or all of these works for personal or classroom use is granted without fee provided that the copies are not made or distributed for profit or commercial advantage AND that copies 1) bear this notice in full and 2) give the full citation on the first page. It is permissible to abstract these works so long as credit is given. To copy in all other cases or to republish or to post on a server or to redistribute to lists requires specific permission and payment of a fee. Contact Publisher@InformingScience.org to request redistribution permission. relationships between supervisor and student, and sound support for the research process. Supervisory relationship and practices are the focus of much research, which frequently considers variations in practice from the perspective of the traditional functional, dyadic relationship. More recently such research is also concerned with issues of power (Grant, 2008; Manathunga, 2007, 
2011), where there is a suggestion that the ostensibly collegial student-supervisor relationship more nearly resembles that of master and slave. Focus on supervisors has also considered interactions using dialogues (Cargill, 1996; Pearson, 1999; Wisker, 2005, 2012) and how supervisors learn from being examiners (Wisker \& Kiley, in press). The supervisor is not the only provider of support for doctoral students. There is a growing body of research concerning programs providing peer support and other support provided by communities of critical friends (Shacham \& OdCohen, 2009; Wisker, Robinson, Trafford, Warnes, \& Creighton, 2003). Little, however, has been written about support for supervisors. Most research on cultural difference deals with culture of origin rather than of discipline. and the diversity of doctoral students has been largely discussed in relation to differences brought by cultural diversity (Grant, McKinley, Manathunga, Knowles, Singh, Wisker, \& Robinson, 2010; Manathunga, 2011; Singh, 2009; Wisker \& Robinson, 2012; Wisker, Robinson, \& Jones, 2011) emphasizing the importance of recognizing culturally inflected modes of knowledge construction and expression. This paper explores how cultural differences in academic disciplines are reflected in the supervisory process, and how supervisors on cross disciplinary development programs can benefit from sharing experiences and best practice between and across those disciplinary differences.

University supervisor development programs to develop supervision practices are offered in many universities in the UK, Australasia, Europe, and South Africa (Wisker, 2012). In the main they aim to enable colleagues to develop the professional practices of supervision from guiding projects to personal professional support for the development of academic identity, rather than to enforce identity of practice. Those of us who work with supervisor development programs may be aware of the differences in supervision, of the construction and completion of the research project and the shape of the thesis itself in terms of another cultural difference to that of origin, that of discipline culture. Discussions in supervisor development programs have revealed disciplineinflected tensions in the definitions, encouragement, and recognition of congruity and diversity in the thesis. Disciplinary differences also seem to affect expectations of roles, relationships, and balances of power in the supervisor, student, and examiner relationships involved in doctoral achievement.

Most research into cultural difference in the context of supervision focuses on culture in terms of origin rather than discipline, and both our published work and work in progress (Claesson, Hallström, Kardefors, \& Risenfors, 2011; Wisker, 2001; Wisker \& Robinson, in press) considers cultural diversity among supervisors and postgraduates. An interest in discipline as culture, the differences this entails, and the ways in which supervisors can share and benefit from such differences prompted this current research which considers supervision courses as cross-cultural knowledge experiences. Here we perceive discipline as a form of culture and the supervision courses as context in which such discipline culture differences are initially often problematized then expressed, clarified, theorized, and shared in ways which we hope are beneficial to the supervisors and their students.

\section{Research Question}

In some university courses on supervision of postgraduate students the full range of disciplines are represented, so discussions about supervision and disciplinary differences arise as colleagues consider what can be thought of as generic good practice. As facilitators on such courses, our interest in the issue of disciplinary cultural differences was sharpened as a result of a participant's rather challenging comment:

The problem with these supervision courses is that they are run by social scientists but we are medical scientists and their supervision practices and problems have nothing to say to us. (Participant, 8) 
This prompted our thinking first about disciplinary differences in research, in the thesis and also in supervision practice, and then about whether and how we could use the discussion around such differences to encourage participants to think deeply about supervision rather than feeling they were being trained to work in a totally homogeneous, discipline-free way. This led to our conducting research with the supervisors on the program, with their approval, focusing on (a) their written responses as part of the program, and (b) on accompanying interviews.

Our research question is

1) In courses for supervisors, what kind of disciplinary culture differences do participants and facilitators consider notable?

Following this we asked:

2) How might engaging with such differences enhance the conceptual and practical levels and usefulness of supervision courses?

\section{Literature}

\section{Cultural Difference}

A lot of the literature on cultural difference in research learning and supervision emphasizes that of culturally inflected knowledge constructions which students bring to their research in a globally mobile research environment. Global mobility is also experienced by supervisors, who frequently find themselves researching in one country that is not their country of origin and supervising students from a third country, where issues of cultural difference in terms of knowledge construction and learning behaviors as researchers both challenge and enrich supervisor/student and research learning relations.

Some response to cultural difference would include support for language at tertiary literacy levels, the accessibility of language, research matter, and supervisory and training discourses with which students must become familiar, each of which comprise power-inflected issues (Grant, 2008; Manathunga, 2007, 2011; Wisker, 2012), while other responses recognize culturally constructed and expressed research (Wisker \& Robinson, 2012). One of the authors of this paper conducts supervisor development workshops worldwide and is impressed by the multicultural mix of supervisors, students, and contexts. From these workshops it appears that supervisor and student cultural variety and mobility are probably most marked in the sciences and medical sciences. Both authors have experience working in Sweden, with supervisors who present both cultural and discipline diversity. Considering various interpretations of culture, Holley (2011) explores how doctoral (in this instance neuroscience) students understand and use culture in terms of their research learning where culture is considered "as an active set of symbolic meanings and practices exhibited by members of a group" (Swidler, 1986, 2001). Culture is seen by Holley (2011) as a set of tools, a repertoire (Swidler, 2001; Tilly, 1992), and an approach. She argues that "culture can be seen in a causal role; that is, the strategies of action pursued by group members are cultural products. Individuals pursue such strategies within unique social contexts, which influence decision making and behavior. The ritualistic practices and symbolic meanings held by a group provide individuals a means to organize reality" (Holley, 2011, p.80). Her work sets out to "understand how doctoral students employ various aspects of culture as part of the socialization process" (Holley, 2011, p.79) and builds on research conducted by Tierney (1997), Schein (1993), and Weick (1995).

Holley (2011, p. 81) reminds us that "Academic work takes place in the intersection of multiple cultures, including the discipline, the department, the institution, and the profession (Becher \& Trowler, 2001; Holley, 2009; Tierney, 1997)." So that whatever the cultures they enter and in 
which they research, "Doctoral students must negotiate those norms inherent to these multiple cultures" (Holley, 2001, p. 81). We should like to argue that supervisors also negotiate these cultures and have a role in supporting doctoral students in their negotiation of departmental discipline and knowledge construction cultures. Much of these cultural elements are implicit, seemingly acquired by osmosis. Supervisors might well be so steeped in the cultures they perceive as being "normal" that they could find it useful to explore what they mean in theory and practice in order to see them more clearly and see them as part of a range of cultural behaviors which are easier grasped if made apparent and understood.

\section{Supervisor Development}

Supervisor development programs have become widespread internationally. In the UK this follows the Dearing Report (Dearing, 1997), Metcalfe report (Metcalfe, Thompson, \& Green, 2002), and the work of UKGrad/Vitae, including the Researcher Development Framework report (Vitae, 2011). In Australia, for example, McCormack and Pamphilon (2004) ran a program enabling narratives of supervision to be developed and exchanged, while Geof Hill's (2011) course at Queensland University of Technology culminates in the sharing of supervisor narratives online. Additionally, this has also become an area of research and a number of international conferences specifically focus on postgraduate learning and supervisory practices. The Quality Postgraduate Research conferences, based in Adelaide since the 1990s, focuses on research learning, supervisory practices and the variety of supervisor development programs, as do the University of Stellenbosch, South Africa, conferences since the mid-2000s.

Supervision is a role which is continually 'becoming' (Deleuze \& Guattari,1987), engaged and defined both with and by community and practice, theorized by Wenger as a "profound connection between identity and practice" (Wenger, 1998, p. 149). We define who we are through negotiation and reconciliation of multiple trajectories related to our varying positions of membership of multiple communities. One such community is that of culture of origin, another is culture of discipline, as explored in Tony Becher and Paul Trowler's (2001) Academic Tribes and Territories, where disciplines provide 'identity communities' (our term) as well as professional practice behaviors, of which research learning and its supervision are a special case.

Becoming a supervisor entails adding the supervisor identity into the rich balance of discipline specialist, teacher and facilitator of learning, researcher, contributor to university and community service, course leader, and the rest of life. This entails reflection and balance between roles. Ongoing debates about the importance of research as an essential learning activity help us, as supervisors, to concentrate on developing research methods and skills with our students. However, tensions exist in the institutional and international contexts in which we operate as supervisors. One of these is the tension between supervisory responsibility and control: the need for students to grow as independent learners and researchers, set against mentoring, management, and support for research development. Increasing commodification of knowledge and research establishes an uneasy causality between numbers of doctoral graduates and national economic wealth. In the utilitarian model, students are perceived as producers of knowledge, products of the research learning, supervision system, and completion numbers aim towards national targets. Another tension supervisors identify is that of time to completion, and adequate challenge to encourage students to both take the risks demanded by research and to make the 'learning leaps', to cross conceptual thresholds (Kiley \& Wisker, 2010; Wisker \& Robinson, 2009) producing research that is exceeding the passable, achieving conceptual, creative, and critical, sometimes even groundbreaking results (Wisker, 2010).

Supervisor development programs have a duty to induct supervisors into the identity, roles, and practices of supervision, and the enabling and supporting of research learning among postgraduates. These programs frequently bring together supervisors from different disciplinary cultures. 
Issues of different constructions of knowledge, approaches, worldviews, and practices which surface during the course of any workshop or program could be seen as both challenging and enriching. Educational developers facilitating such programs are very familiar with disciplinary approaches to learning and teaching presented in workshops on a range of topics. A major challenge is often to enable articulation of (i) the specificity of the context and approach in which a colleague works in his or her role and discipline; and (ii) the appreciation of general issues of roles, rules, regulations, and practices. In learning at this level, cross-fertilization of approach, theory, and practice could lead through discussion and sharing to conceptually robust, diversified, rich practice for supervisors and, beyond them, their postgraduate students.

Different conceptions of supervision underlie both different disciplines and the cultures and practices of supervisor development programs. In a 'communities of practice' approach which appreciates situated learning (situated in the discipline context and here in the supervisor development program) the participants "do things together, negotiate new meaning, and learn from each other" (Wenger, 1998, p. 102). Pearson and Brew (2002) see this "offers a conceptualization of learning that avoids the separation of learning from knowledge production," (p. 142) which Smith (2000) notes as a concern raised by students. Social scientists and those who engage in research related to their professional practice might well see research learning as a social practice itself, situated in the professional context of the university and the supervision interaction, as well as the profession. Supervisors and students in the applied sciences are, according to Delamont, Atkinson, and Parry (1997), more likely to see research learning as enculturation, in a mode related to apprenticeship where students are guided by supervisors to conduct research in certain ways, for example, for scientists, becoming part of the laboratory with their own culture and acceptable behavior. Students engaged in the sciences at all levels learn "pedagogic continuity", "the socialised skills of laboratory work, through which research problems are transmitted" (Pearson \& Brew, 2002, p. 142). Golde (2005) points out that departmental disciplinary culture is an important factor in doctoral student persistence and satisfaction.

We suggest that the context of the supervisor development program itself should enable both discussions about how research learning and supervision take place and discussions about cross fertilization from the different disciplines' conceptions of research learning and supervisory practice. Pearson and Brew (2002) note that in supervisor learning and development programs:

Supervisors have to extend their understanding of the nature of research and supervisory practice in order to deal with variations in these learning and career goals of different students, and in differing institutional, disciplinary and professional contexts. This is the curriculum which has to be negotiated. Of particular relevance is the emphasis on learning through self-awareness. (p. 143)

We also argue that such extension and negotiation offers the opportunity for 'learning leaps' or conceptual threshold crossings (Kiley \& Wisker, 2010; Wisker \& Kiley, in press), for supervisors, who can engage more deeply, conceptually, and meta-cognitively with the processes of supervision when comparing and sharing with supervisors in other disciplines. This is also enabled by engagement with the explicit problematizing and theorizing of practices which a multidisciplinary supervisor program offers, when diversity is brought into discussions.

\section{Methodology, Methods, and Context}

This study involves reflections on the cross-disciplinary supervisor development program, on challenges, and potential benefits for good practice raised during the program. Some of the examples of challenges and good practice were collected through course papers produced for assessment by course participants, some by interviews with the course participants, and others from the two program facilitators, the authors of this paper, who observed the programs while running 
them. All responses are discussed in the context of theory related to cross-cultural supervision and supervisory development program experiences more generally.

The course on which our research study is based is one of several for university teachers at one of the largest universities in Sweden. In order to maintain high quality in PhD-theses, all supervision courses are obligatory at this university for those researchers who want to become supervisors. The course studied is in English, although there are other courses in Swedish, and each includes all faculties, so there is a mixture between researchers from the faculties of arts, medicine, natural science, social science, education, and humanities. During one term, participants meet for six days, spread over the term, and there is one obligatory observation of a supervision in practice. The participants arrange the observation in which they experience supervision carried out in a faculty, which is as different from their own as possible. Another part of the course deals with roles and regulations in relation to supervision of the $\mathrm{PhD}$; there is also a book to read and a final course paper to write on an issue of interest to themselves. The main part, however, is a two-day workshop where the participants discuss themes and practices relevant to supervision in general. In this study we have had the opportunity to explicitly observe the participants during this workshop, as well as to reference their course papers and to conduct interviews with the participants. All data has been gathered taking full account of ethical considerations and with the full agreement of the course participants. Nothing of what they have written or said has affected any response to their assessment on the course. No names have been released and all data is kept confidentially

We focus on the perceptions of participants, supervisors, and supervisor developers of the issues, challenges, and visible benefits of cross-disciplinary supervisory development programs. In terms of such programs, we ask how we both meet and develop practices to go beyond meeting the needs of the different groups, to realize mutual understanding, enhance cross-disciplinary research and supervision possibilities, and enable benefit from cross-disciplinary knowledge construction. As teachers and supervisors, we are translators of experience between supervisions, between individuals and contexts, and of the experiences of others into our own. In the developing context of cross and multidisciplinary work, we need to know about different research and supervision paradigms to enable enriching mixtures of styles and forms of knowledge construction. It could be argued that supervisor development program facilitators need to work across disciplinary 'boundaries' and differences - to bring in the research, fill out the context, and enable people's voices from different, authentic origins.

The method for this piece of practice-based research is one empirical study divided into two sections. In the first section, the observation and analyses focus on the challenges, benefits, and potential of the course to enable cross-disciplinary exchange, theorizing, and building of good practice. The second research section consists of (i) an analysis of 17 papers, each between 2-6 pages, produced by the course participants. 11 of the papers engaged with issues of disciplinary difference and so these form the basis of this research article. The 11 participants whose papers are referred to here were then interviewed as a follow up so (ii) their interview responses are also included. The research questions (above) form the focus of both (i) the scrutiny of course papers and (ii) the direct interview questioning of course participants, and the responses are deliberately intermixed here to form a coherent thread of argument. Participants came from the full breadth of faculties in the university - medicine, sciences, humanities, arts, social sciences. Participant responses are numbered.

The interpretation of the final course papers and the interviews is inspired by hermeneutical theory developed by Paul Ricoeur (1983). In Ricoeur's critical hermeneutical theory, participation is a constant process of interpretation, in which the dialectics between pre-understanding and new experience open up explicitly expressed contrasts, or "fields of tensions" (Claesson et al., 2011). In his early work, Freedom and Nature (2007), Ricoeur elaborated a dialectic view of human ex- 
istence, identifying two different views on humanity - often considered to be mutually exclusive: the human regulated by law and the human as a reflecting subject, desiring to desire (consciously wanting to want, to act, rather than merely just existing in a situation) over her own existence. Unlike other phenomenologists such as Husserl and Derrida, Ricoeur argued for an active subject and object and an element of choice, morality, meaning, the will and wish to decide to act beyond a mere understanding of being in a situation. Ricoeur was also constantly involved in communication and used the concept of 'fields of tension' in most of his work as a starting point for inquiry (often focusing on contraries or differences and suggesting links and unities for instance of tragedy and hope, ethics and politics) (Abel, 2011). He moves beyond exhibiting fields of tension and seeks reconciliation, shown for example in the interlacing of the views of humans as regulated by law and as reflecting subjects (Uggla, 2010). One of our concerns, then, was that of reconciliation between different disciplinary views, and mutual benefit from the exchange of such views.

Our understanding about different disciplinary based PhD cultures developed from discussions during the course with the participants and our discussion and interpretation of the observation data. We scrutinized and re-scrutinized the empirical data from the course papers and the interviews and from those readings derived (i) a pattern of understanding of what it means to be a $\mathrm{PhD}$ student constructing research learning in different disciplinary contexts and (ii), related to this, the discipline-inflected, differing approaches of the supervisors.

In this essay we will first present the data through quotations from course participants' responses in their course papers, from the interviews, and from our own observations; secondly, inspired by critical hermeneutics of Paul Ricoeur, we will describe fields of tensions related to the crosscultural differences that we discovered.

\section{Findings}

Our findings present issues of awareness of discipline cultural difference, interpreted in terms of Paul Ricoeur's "field of tensions" (Claesson et al., 2011; Ricoeur, 1983). We discovered three major fields of tensions, explored below through participant interviews, participant course essay quotations, and analysis. Participants are numbered to retain confidentiality:

1) Working in a laboratory versus individual ability and expectation to read, analyze, and write.

2) Working in a team versus studying alone.

3) Formulating own research question versus taking part in established project.

In the final papers written by the participants on this supervision course, the issue of discipline culture was directly discussed in different ways. One participant (4) writes:

My awareness of culture in the academic world began when I started my $\mathrm{PhD}$ studies. Then I understood my own culture as something distinct. Before that I just regarded it as the way things are in life. (4)

You become aware of your own culture, whether of origin or discipline, as you are confronted with something new or different. On this course participants highlighted differences between disciplinary cultures. In this paper, we interpret disciplinary culture as something of which you become aware, and this awareness helps to challenge your established attitude. The differences between those who came from the faculty of science or medicine, where the laboratory was the focus, and those who came from social sciences and humanities or art, where reading, analysis, and writing are the focus, emerged as main topics discussed and referred to as differences between cultures. 
Disciplinary culture was discussed openly and is the focus here, rather than differences between countries of origin and culturally inflected research learning arising from the modes of knowledge construction prevalent in different contexts, for example, those of Confucian heritage learners or Arab world learners.

Manathunga's postcolonial theory establishes notions of 'contact zones' (2007). While she applies this to cultural origin context contacts, it is a useful tool to enable theorization of the disciplinary cultural 'contact zones' experienced and enabled in the supervisor development program.

\section{The Culture of the Laboratory}

In six of the papers the participants explicitly dealt with differences between faculties in relation to what research a $\mathrm{PhD}$ student is expected to conduct and how they carry out their research in practice in order to succeed. Many participants indicate that what they actually do with $\mathrm{PhD}$ students is to work together in the laboratory environment.

1. We work in smaller or larger teams, on tight schedules, especially in competitive areas, which are also influenced by expectations from grants agencies. 2 . There is little space for formulation of a research question or confront theories from the students' side. 3. The student is expected to perform experiments in the laboratories. 4. Consequently, students are employed full time and doctoral positions are often seen as a form of employment to pursue interesting projects and not a journey of learning. 5. There is a constant need for performing the good experiments, from which results can be built into a publication (Participant 12).

This is a rich, no nonsense response. This participant (12) formulates in a few points what he finds most significant for a laboratory-environment where the $\mathrm{PhD}$ student should perform his/her part. Some of what is pointed out here is not easily connected with what is important in the social sciences or humanities. The main performance takes place in the laboratory - instead of writing texts. Another participant (5) describes work in a laboratory.

During an average day in the lab a hard working student will make about 30-40 attempts and depending on the cell type get about 0-4 usable measurements. Depending on the experimental details there will be stretches of several weeks without producing any usable data at all (Participant 5).

They indicate the necessity of not making any mistakes in the experimental design and note that there are many attempts, very few of which might ultimately be useful. Perhaps this can be translated to the field of social science where field-notes are taken week after week and still the data is hard to use directly in the thesis.

One supervisor (Participant 5) defines an incident with a PhD student who had prepared for a presentation:

He never got the chance to present the data himself but rather we rushed through his figures due to the lack of time. I assumed that he, after just listening for more than three hours straight and then not even getting the chance to present his data properly, would walk out of the meeting rather disappointed. However, when talking to his supervisor a few days later I learned that the day after the meeting he said "I have never been so motivated in my entire life". When I asked why he found this meeting so stimulating, his reply was that he for the first time got an overview of the whole project, understood how his work fitted in, realized how interesting the project was and became more confident. (Participant 5) 
He did not have the opportunity to present himself, but instead gained a valuable overview of the project, understood what it was all about, and realized he was actually participating in a very interesting project. The story illustrates well the situation in which $\mathrm{PhD}$ students who are employed in huge projects have control over only a small part of the research. Two other main differences in comparison with the social sciences or humanities are the interpretation of formulating a research question and engaging in a dialogue with the literature. Laboratory-based $\mathrm{PhD}$ students are usually given the question, which is likely to be part of a funded project, and they later refine it to make it more their own, rather than generating questions themselves from their own interest and/or practice.

Dialogues also differ between disciplines. One participant (11) discusses what he read in the course literature about "dialogue with other experts" in relation to their own interpretation.

'Dialogue with other experts' may form the basis for research in the liberal arts/social sciences fields, but science and health disciplines are rooted in the scientific method, i.e. theoretical descriptions of phenomena that are experimentally testable. While a 'dialogue with experts' (i.e. publications, conferences, etc.) is a natural "output" of any research discipline, it hardly forms the basis for most research in and of itself (Feigener, 2011). (Participant 11)

The way to understand 'dialogues with other experts' is here narrowed down to the 'output' of research. To this participant (11), his own experience of dialogue is strongly connected to the moment when the result can be presented. Before that the work in the laboratory is the focus. This example shows that there are differences among participants in using and understanding the term 'dialogues'. Differences between research discipline cultures emerge in both the observations and the discussions in the program, and some participants comment directly on such differences.

\section{The Culture of Reading, Analysis, and Writing}

Reading, analysis and writing are mentioned as foremost activities among social scientist, humanities, and arts participants. One arts participant (2) makes a useful comparison, showing cross-disciplinary cultural learning when she comments in her paper on the quality of the laboratory results, comparing them with arts and humanities, where "the quality of the text is an important lab result" (Participant 2). Another, (Participant 14) from Business Administration, Social Sciences, considers dialogue and the development and ownership of knowledge:

I remember my discussions with the supervisors about my theoretical and methodological perspective of studying the topic of my thesis. Those discussions were often long and sometimes exhausting. (Participant 14)

Here supervisor and PhD student discuss the theoretical framework. At the end of this description the participant (14) remarks that it is an "Unequal power-filled pedagogical relationship, which is affected by discourses of power and authority (Grant and Graham, 1999)" (Participant 14). The understatement in this paper is that the participant clearly feels there ought to be an equal discussion. This equality is not at all on the agenda in the laboratory-work described above.

Participants from the social sciences, humanities, or arts often use the same theories they use for writing theses or articles to write the final course paper. However, only one of the participants (2) directly addresses the differences between writing cultures as interpreted here.

Outputs and publication are also an issue. Some of the participants comment in their final course papers on what they have learned from the obligatory observation experiences. Discipline differences emerge as an issue when observing a science supervision for participant (2), from the Faculty of Arts, who notes that: 
What actually came as something of a surprise was how much of the work seems to be about managing not only networks of information, but social networks of researchers as well, including a kind of social meta-level where timing of the 'new value' of published results is managed for maximum impact. (Participant 2)

Timing of publications, the importance of impact factors, the awareness of networking, and the constant talk about 'managing the publications by results' (Participant 2) were all a surprise to this participant.

In one paper, the participant (1) discusses how to deal with differences in a university context. $\mathrm{He}$ worked with people from different institutions in a large project and considered issues about different backgrounds and experiences. He writes about having several supervisors:

In the ideal case the two supervisors should have different background and experience, complementing each other. For example a professor with several years' experience of research, clinical work, and supervision, confident in the roles of the university, familiar with all the great names in the field. ... This could also be completed with a mentor from the outside, maybe from another faculty or the industry. (Participant 1)

Supervising students in groups where researchers from different fields work together in crossdisciplinary projects might increase in the future, and being aware of the differences between different discipline and faculty-based constructions of knowledge, research learning, supervisory cultures, and practices should be of direct use in such future developments.

\section{A Critical Hermeneutical Interpretation}

Our understanding of the experience of the participants is explicable by using Ricoeur's (Claesson et al., 2011; Ricoeur, 1983, 2007; Uggla, 2010) concept of 'field of tensions'. Here we present and discuss three of those fields.

1) Working in a laboratory versus individual ability and expectation to read, analyze, write.

You develop certain skills related to the research conducted during your time as a $\mathrm{PhD}$ student. The skills developed in science and medicine are frequently those to set up a really good experiment, while in social science and humanities they are mainly to formulate a good research question and research design, develop a dialogue with the literature in which you situate your own research and contribution, and to express yourself in writing. Students in different discipline areas develop different skills; however, there are similarities in the skills needed to set up the perfect experiment and those needed to formulate one's thoughts in a text.

Skill behind both a good experiment and writing derive from the ability to focus, analyze, maintain, and complete the research rigorously. Consequently, in a course on supervision it might be useful to expose and discuss both the differences and the similarities between what $\mathrm{PhD}$ students should be good at in order to conclude their research and theses.

2) Working in a team versus studying alone.

There is a distinction between how doctoral students carry out their work on an everyday basis in science in comparison to those who work in art, social sciences, or humanities. In science or medicine, PhD students usually take part in a project, which already exists before they arrive. During the working day they meet the professor and other PhD students, they discuss their joint work and integrate socially. This is rarely the case in art, social sciences, or humanities. In those faculties instead, doctoral students carry out an individual project, which can be isolating and lonely and requires consistent motivation. It also makes the instances of supervision very important because they rarely happen as an eve- 
ryday event and will probably need to be booked in advance. In social sciences, humanities, and arts, interaction, joint work, being part of a learning community, and 'the research society' are also important and so need to be explicitly organized, encouraged, and managed by supervisors and doctoral students.

3) Formulate own research question versus take part in an established project.

If the doctoral student takes part in a big project, the research question is probably already formulated by the researcher who started the project. The question the student deals with contributes to the project as a whole, as one aspect of many. This way of starting a research career can be contrasted to the research question formulated in art, social sciences, or humanities. In those faculties the doctoral student might take a long time finding out how to formulate his or her own research question.

However, whoever formulates the research question, the doctoral student must make it his or her own in order to penetrate the field of study, so the question must be doable, challenging, sharp and exciting for the student.

In postgraduate supervision courses these fields of tensions are very visible and discussed as different during the course. However, we would argue from our own experience and observations that practice is often less clearly differentiated so that there are teams and communities on large funded projects in both the social sciences and some arts and humanities, and all students have to focus at some point on the fine-tuned elements of their writing practice, although this might well be carried out at different stages in their work, with scientists writing up towards the end of their work, and social scientists and artists writing throughout. Further work needs to be carried out with supervisors and postgraduates concerning these similarities and precise differences to more fully appreciate the opportunities for learning from good practice in similar and in different behaviors based on discipline culture, and analysis using Ricoeur's 'fields of tensions,' and concern for reconciliation (see below) could be further explored at this point.

Another issue emerges with the very focus on the principles and practices of supervision in such a cross-disciplinary culture course. Some participants find the whole process of development itself too orientated towards social sciences as a research area, and the use of education and social science processes and language alien to ways in which they construct knowledge or express their experiences as supervisors and researchers.

This rich mix affects the supervisory practice relationship with students and the construction of knowledge and its expression. The participants discuss and appreciate the variety of practices; the setting of ground rules, structure, and systems, often applied differently in different disciplines; the need for rules and dialogues; supervisory interactions at different points in the research project development or with different students; the need to attend to personal development issues of students, such as family or personal crises, health, welfare, and emotional wellbeing; and the learning development and conceptual threshold crossing moments in research.

In the discussion of processes and practices, disciplinary differences emerged over moments at which students made specific learning leaps or conceptual threshold crossings in the research, and modes of supporting or "nudging" them. The supervisor development program offered opportunities to identify practices, challenge them, and highlight why and how we support and facilitate research and research development in different disciplinary and cross disciplinary contexts.

Comparisons and cross disciplinary culture dialogue began to enable theorizing, sharing, and developing good practice. Further work will focus on the facilitators' and the participants' perceptions of this developmental process. 


\section{Facilitators' Reflections}

Pearson and Brew (2002) identified four main concepts of research learning and discovered that different disciplines were unlikely to lead rigidly to the embracing of one concept over another, one set of practices over another. They note:

A somewhat surprising finding of this study was that different conceptions of research are not tied to disciplinary differences, although this was initially anticipated. For example, in scientific and technical disciplines, all four conceptions of research were present, as they also were in the humanities. This is consistent with Becher's (1989) analysis of the culture of academic departments. He demonstrates that individuals' conceptions of research are a function of a complex set of factors, of which disciplinary allegiance is only one. A further finding of the investigation was that researchers carrying out similar kinds of research - for example, laboratory-based research, collaborative team-based research, individualised investigations - did not necessarily share the same conceptions. This has considerable implications for supervision. It means that the supervisor cannot assume that the student has the same idea as themselves about what they are doing when they are carrying out research. (Pearson \& Brew, 2002, p. 145)

However, colleagues in supervision courses have emphasized differences of approach to research, the doctorate, and their supervision.

I became aware that through their airing of differences in approaching even as basic an issue of as the development of an area of research, a research question, supervisors from different disciplines engaged with research into supervising and researcher development - eg. the finding that an early stage enabling conceptual threshold crossing is one where students begin to own, theorise, work conceptually and critically with their own ideas in their field - so these differences presented challenges to established modes of behaviour as teachers and learners, and knowledge constructors, as researcher and supervisors - if the question is given to the student or they develop their own - how can problematising, theorising and engagement with knowledge construction and effective suitable research design be carried out? (Facilitator 1)

Even within the same discipline there may be different research traditions and different subdisciplinary cultures. How do we run courses for supervisors to deal with such differences? The course under discussion is cross-cultural, taught in English, and attended mostly by people who speak only some Swedish and come from different parts of the world. The participants often consider differences in academic culture, and we all wondered whether the disciplinary language in which to discuss supervision should be that of the social sciences and education, which privileges the process of writing up a thesis.

One of the aims of the research is to explore these differences, and another is to begin to suggest that supervision courses and participants can enjoy mutual learning; reconciliation, and enrichment enabled by reflection on, sharing, and building from disciplinary cultural differences. Future work will further develop issues of the cross-disciplinary experience of supervisor participants and facilitators in supervisory development programs. It will explore the challenges and benefits and the development strategies, using interviews with supervisor participants, and will move beyond the Swedish context, exploring the challenges and the benefits of international examples of multi and cross-disciplinary supervision development programs. It will begin to offer fuller and more explicit suggestions about ways in which supervision courses and participants can develop mutual learning and metacognitive appreciation of research learning for diversity, reconciliation, and enrichment. 
The participants undertook observations in institutions different to those in which they were used to working. They appreciated the observations and noted that disciplinary differences were even more obvious than before.

A rather sensitive issue emerged even before the beginning of the course which is focused on in this paper, that of the potential for different levels of challenge and of the quality of the research learning:

For me the issue between science and social science first emerged when I ran a program at $\mathrm{x}$ (medical science institution in Ireland) - after considering stages where doctoral students evidenced that they had learned to conceptualise the work - one medical colleague commented that they thought their students probably did not necessarily ever need to do this - so was their work at a standard sufficient for a PhD? Or were we defining that standard too narrowly? (Facilitator 1)

One way to deal with these discussions is to focus on differences to start with. That could be done by explicitly presenting the difference in cultures, which, in turn, will make each participant simultaneously aware of his or her own and other cultures. There could be a panel debate between representatives from different faculties, explaining the ways supervision is carried out in their faculty or department. While some of the materials to inform such discussions can emphasize disciplinary difference in supervision and in research learning, some others from research into supervision and research learning demonstrate their similarities. Resultant debate enables participants to step back and operate metacognitively, considering the processes of research learning and of supervision, and deciding what is suitable in different contexts. It offers the opportunity to share experiences and perceptions of difference, identifying the usefulness of varied good practice, and can enhance the reflection and metacognition of processes and underlying beliefs of both supervision and research learning.

The quotations - from experience and from research - could prompt discussion of discipline differences in supervision and research learning, leading to more profoundly, conceptually aware forms of supervisor learning, and then to begin to develop a repertoire of supervisory practices.

\section{Discussion}

In the light of diversity, change, and demand, supervisors and institutions need to focus on supervisory developmental needs and practices to benefit from the varied culturally inflected knowledge exchanges, where culture is here understood as both related to origin and to discipline. Our argument is that disciplinary differences are a form of cultural difference insofar as they relate to different constructions of knowledge, research designs, processes, and writing practices. The questions and assumptions underlying our research with supervisors from different discipline cultures on research supervisory development programs relate to differences in research learning and related supervisory practice affected by discipline. They relate also to the reflection and metacognition enabled by engaging with the theorizing and practical processes of the supervision program itself. This includes the potential benefit of discussion, mutual appreciation of discipline culture differences, and the potential for enriching supervision and research learning development. Enrichment, we suggest, comes about through sharing and mutual understanding of both the conceptualization and the practices of supervision, between group members, between disciplines, and leads to enhancement of professional and sensitized supervision practices, of benefit to research learning. Two assumptions emerge about what cross-discipline-cultural courses might offer.

It could be argued that if you only see postgraduate research and supervisory practices from your own disciplinary cultural context you might neither question and explore it nor deal with the fixed behaviors or issues that any disciplinary inflected modes of supervision might produce. Established learning behaviors derived from study in particular disciplines, and modes of supervision 
experienced when being a postgraduate, might affect and drive what is seen as normal and acceptable as modes of supervision and research learning. It could be argued that behavior and stages of supervisor development affect the response to supervision programs and the opportunities they offer for working across discipline cultures on the processes and practices of supervision. The functional approaches of new supervisors could drive their need to define what is "right" and "appropriate" so that they can manage the supervision process as a job, now. As a supervisor you have the opportunity to question and explore what you take for granted, through cross-disciplinary comparisons. As a result, you can work to share the modes of knowledge construction and articulation in the various forms of research and thesis, deal with issues in research learning and supervision where they exist, and improve practice.

\section{Conclusions}

This research focuses on the perceptions of supervisor participants and on the facilitators of the supervisory development program, considering the issues, challenges and visible benefits of cross-disciplinary cultural development programs. Our work explores and illuminates the perceptions of supervisor participants in terms of awareness both of disciplinary cultural differences in knowledge construction at research learning levels and in supervisory practices. We explore perceptions and suggestions of the potential for conceptual threshold crossing, enhanced learning feeding into practice for supervisors who can become aware of what and how other discipline practices can highlight and problematize. Our work begins to suggest ways in which supervisory development theorizes as well as teaches/trains the functional activities of supervision. To do so, we argue, such development needs these different discipline inputs, discussions, and debates. As supervisors we are translators of experience between supervisions, between individuals and contexts, and translators of the experiences of others into our own. In the spirit of Ricouer's critical hermeneutic and the way of discerning fields of tension and Ricoeur's way of finding means to achieve reconciliation we can here trace a way to understand how to work in courses with future $\mathrm{PhD}$-supervisors. In the context of cross and multidisciplinary work we need to know about different research paradigms and supervision paradigms to enable the enriching mixtures of styles and forms of knowledge construction in research and in research student supervision

\section{References}

Abel, O (2011) Paul Ricoeur's place in the French intellectual landscape at http://olivierabel.fr/ethique-etpolitique/paul-ricoeur-s-place-in-the-french-intellectual-landscape.html (accessed Jan20 2013)

Becher, T., \& Trowler, P. R. (2001). Academic tribes and territories (2nd ed.). Buckingham: Open University Press.

Cargill, M. (1996). An integrated bridging program for international postgraduate students. Higher Education Research and Development, 15(2), 177-188.

Claesson, S., Hallström, H., Kardefors, W., \& Risenfors, S. (2011). Ricoeur och empiriska studier [Ricoeur and empirical studies]. Pedagogisk forskning i Sverige, 16(1), 18-36.

Dearing, R. (1997). Higher education in the learning society. National Committee of Inquiry into Higher Education. London: HMSO.

Delamont, S., Atkinson, P., \& Parry, O. (1997). Supervising the PhD: A guide to success (pp. 1, 8-9, 57, 97). Buckingham: Open University Press.

Deleuze, G., \& Guattari, F. (1987). A Thousand plateaus: Capitalism and schizophrenia. Minneapolis: University of Minnesota Press.

Feigener, M. (2011). Science and engineering degrees: 1966-2008; Detailed statistical tables, National Centre for Science and Engineering Statistics. Retrieved from http://www.nsf.gov/statistics/nfs11316/pdf/nsf11316.pdf 
Golde, C. (2005). The role of the department and discipline in doctoral student attrition: Lessons from four departments. Journal of Higher Education, 76(6), 669-700.

Grant, B. M. (2008). Agonistic struggle master-slave dialogues in humanities supervision. Arts and Humanities in Higher Education, 7(1), 9-27.

Grant, B.M, \& Graham A. (1999). Naming the game: Reconstructing graduate supervision. Teaching in Higher Education, 4(1), 77-89.

Grant, B., McKinley, L., Manathunga, C., Knowles, S., Singh, M., Wisker, G., \& Robinson, G. (2010). Symposium on cross cultural supervision. Quality in Postgraduate Research Conference, 2010.

Hill, G. W. (2011). Diffracting the practices of research supervision. In Vijay Kumar Mallan \& Allison Lee (Eds.), Connecting the local, regional and international in doctoral education. Universiti Putra Malaysia Press, Serdang, Malaysia.

Holley, K. A. (2009). Animal research practices and doctoral student identity development in a scientific community. Studies in Higher Education, 34(5), 331-344.

Holley, K .A. (2011). A cultural repertoire of practices in doctoral education. International Journal of Doctoral Studies, 6, 2011, 79-94. Retrieved from http://ijds.org/Volume6/IJDSv6p079-094Holley312.pdf

Kiley, M., \& Wisker, G. (2010). Learning to be a researcher: The concepts and crossings. In J. H. F. Meyer, R. Land, \& C. Baillie (Eds.). Threshold concepts and transformational learning (pp. 399-414). Rotterdam: Sense.

Manathunga, C. (2007). Intercultural postgraduate supervision: Ethnographic journeys of identity and power. In D. Palfreyman \& D. L. McBride (Eds.). Learning and teaching across cultures in higher education (pp. 93, 95). Basingstoke, Palgrave Macmillan.

Manathunga, C. (2011). Keynote. Stellenbosch University Postgraduate Supervision Conference, 2011.

McCormack, C., \& Pamphilon, B. (2004). More than a confessional: Postmodern groupwork to support postgraduate supervisors' professional development. Innovations in Education and Teaching International, 4l(1) (January-February), 3-4, 25.

Metcalfe, J., Thompson, Q., \& Green, H. (2002). Improving standards in postgraduate research degree programs. A report to the Higher Education Funding Councils of England, Scotland and Wales. Bristol: HEFCE. http://www.ndm.ox.ac.uk/_asset/file/metcalfe-report.pdf

Pearson, M. (1999). The changing environment for doctoral education in Australia: Implications for quality management, improvement and innovation. Higher Education Research and Development, 18(3), 277, $276,282$.

Pearson, M., \& Brew, A. (2002). Research training and supervision development. Studies in Higher Education, 27(2), 135-150.

Ricoeur, P. (1983). Time and narrative (Vol. 1.). (K. McLaughlin \& D. Pellauer, Trans.). Chicago: University of Chicago Press.

Ricoeur, P. (2007). Freedom and nature: The voluntary and the involuntary. (originally pub 1966) Evanstone, IL: North Western University Press.

Schein E. (1993) Organizational culture and leadership in classics of organization theory. In J. Shafritz \& J. S. Ott (Eds.) 2001. Fort Worth: Harcourt College Publishers.

Shacham, M., \& Od-Cohen, Y. (2009). Rethinking PhD learning incorporating communities of practice. Innovations in Education and Teaching International, 46(3), 279-292.

Singh, M. (2009). Using Chinese knowledge in internationalising research education: Jacques Rancière, an ignorant supervisor and doctoral students from China. Globalisation, Societies and Education 7(2) 92107.

Smith, B. (2000). The challenge of making ends meet in postgraduate research training. In M. Kiley, \& G. Mullins (Eds.), Quality in postgraduate research: Making ends meet. Proceedings of the 2000 Quality 


\section{Impact of Cross-Disciplinary Culture}

in Postgraduate Research Conference (pp. 25-29). Adelaide, Advisory Centre for University Education, University of Adelaide.

Swidler, A. (1986). Culture in actions: Symbols and strategies. American Sociological Review, 51(2), 273286.

Swidler, A. (2001). Talk of love: How culture matters. Chicago: University of Chicago Press.

Tierney, W. (1997). Organizational socialization in higher education. Journal of Higher Education, 68(1), $2-21$.

Tierney, W. (1988). Organizational culture in higher education: Defining the essentials. Journal of Higher Education, 59(1), 1-21.

Tilly, C. (1992). How to detect, describe, and explain repertoires of contention. Working paper 150. New York: Center for the Study of Social Change, New School for Social Research.

Uggla, K. B. (2010). Ricoeur, hermeneutics and globalization. New York: Continuum Studies in Continental Philosophy.

Vitae. (2011). Researcher development framework report. Retrieved 28 July 2011 from www.vitae.ac.uk/CMS/files/upload/Vitae-Researcher-Development-Framework.pdf

Weick, K. (1995). Sensemaking in organizations. Thousand Oaks, CA: Sage Publications.

Wenger, E. (1998). Communities of practice: Learning, meaning and identity. Cambridge: Cambridge University Press.

Wisker, G. (2001). Good practice working with international students. SEDA Paper 110.

Wisker, G. (2005). The good supervisor. Basingstoke: Palgrave Macmillan.

Wisker, G. (2010). The good enough doctorate: Doctoral learning journeys. Acta Academica Supplementum, 1, 223-242. Retrieved from http://www.ufs.ac.za/journals_ActaAcademica

Wisker, G. (2012). The good supervisor (2nd ed.). Basingstoke: Palgrave Macmillan.

Wisker, G., \& Kiley, M. (in press). Professional learning: How supervisors learn from examining. International Journal for Academic Development.

Wisker, G., \& Robinson, G. (2009). Encouraging postgraduate students of literature and art to cross conceptual thresholds. Innovations in Education and Teaching International, 46(3) (August), 317-330.

Wisker, G., \& Robinson, G. (in press). Examiner practices and culturally inflected doctoral theses. In Discourse (2014 forthcoming, online 2012).

Wisker, G., Robinson, G., \& Jones, J. (2011). The culturally inflected voice: Negotiation and recognition without dumbing down. In V. K. Mallan \& A. Lee (Eds.), Connecting the local, regional and global in doctoral education. Kuala Lumpur: Universiti Putra Malaysia Press.

Wisker, G., Robinson, G., Trafford, V., Warnes, M., \& Creighton, E. (2003). From supervisory dialogues to successful PhDs: Strategies supporting and enabling the learning conversations of staff and students at postgraduate level. Teaching in Higher Education, 8(3), 383-397. 


\section{Biographies}

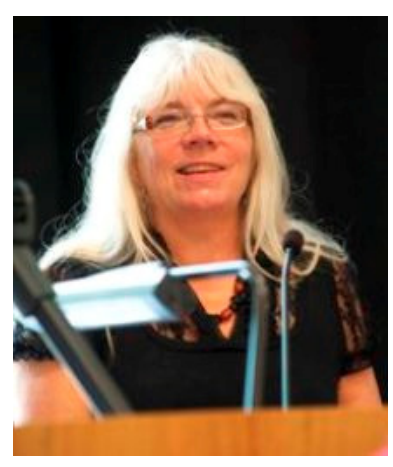

Gina Wisker is Professor of Higher Education and Contemporary Literature and Head of the Centre for learning and teaching at the University of Brighton, UK. Gina specializes in doctoral learning and supervisory practices and her book The Good Supervisor (Palgrave Macmillan2005, 2012) and The Postgraduate Research Handbook (Palgrave Macmillan 2001, 2008) are widely used. Gina led the Higher Education Academy funded 'doctoral learning journeys' project 2007-2010, has been the editor of the SEDA journal Innovations in Education and Teaching International for 15 years, and offers workshops and support for both supervision and writing in Sweden Ireland, UK South Africa, Australasia, and Saudi Arabia.

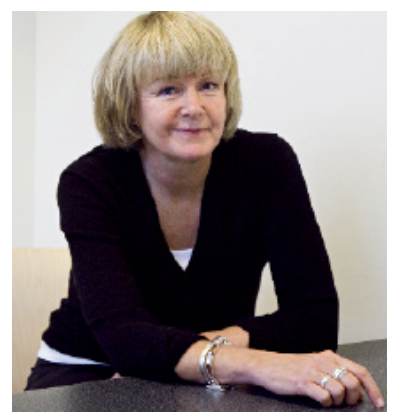

Silwa Claesson is Reader/Associate Professor in Education and the Learning and Teaching Unit at the University of Gothenborg, Sweden. The background for her research is her profession as a teacher and a teacher educator. In her work she deals with the relationship between theory and practice and evaluates whether theories about student learning have had any impact on learning. Her work was initially based in schools, then prisons, and then Higher Education. (See 2004, Teachers lived knowledge. Göteborg Studies in Educational Sciences, 217. Acta Universitatis Gothoburgensis). Her work is influenced by the 'lifeworld' of Merleau-Ponty, and the hermeneutics of Paul Ricoeur. Silwa is involved in postgraduate education through supervision of doctoral students, postdoctoral courses. and supervisor development courses. 